\title{
Management of abortion complications at a rural hospital in Uganda: a quality assessment by a partially completed criterion-based audit

\author{
Natja Mellerup ${ }^{1 *}$, Bjarke L. Sørensen ${ }^{1,2}$, Gideon K. Kuriigamba ${ }^{3}$ and Martin Rudnicki ${ }^{1}$
}

\begin{abstract}
Background: Complications of unsafe abortion are a major contributor to maternal deaths in developing countries. This study aimed to evaluate the clinical assessment for life-threatening complications and the following management in women admitted with complications from abortions at a rural hospital in Uganda.

Methods: A partially completed criterion-based audit was conducted comparing actual to optimal care. The audit criteria cover initial clinical assessment of vital signs and management of common severe complications such as sepsis and haemorrhage. Sepsis shall be managed by immediate evacuation of the uterus and antibiotics in relation to and after surgical management. Shock by aggressive rehydration followed by evacuation.

In total 238 women admitted between January 2007 and April 2012 were included. Complications were categorized as incomplete, threatened, inevitable, missed or septic abortion and by trimester. Actual management was compared to the audit criteria and presented by descriptive statistics.
\end{abstract}

Results: Fifty six per cent of the women were in second trimester. Abortion complications were distributed as follows: $53 \%$ incomplete abortions, $28 \%$ threatened abortions, $12 \%$ inevitable abortions, $4 \%$ missed abortions and $3 \%$ septic abortions. Only one of 238 cases met all criteria of optimal clinical assessment and management. Thus, vital signs were measured in $3 \%$, antibiotic criteria was met in $59 \%$ of the cases, intravenous fluid resuscitation was administered to $35 \%$ of women with hypotension and pain was managed in $87 \%$ of the cases. Sharp curettage was used in $69 \%$ of those surgically evacuated and manual vacuum aspiration in $14 \%$. In total $3 \%$ of the abortions were categorized as unsafe. Two of eight women with septic abortion had evacuation performed during admission-day, one woman died due to septic abortion and one from severe haemorrhage.

Conclusions: Guidelines were not followed and suboptimal assessment or management was observed in all but one case. This was especially due to missing documentation of vital signs necessary to diagnose life-threatening complications, poor fluid resuscitation at signs of shock, and delayed evacuation of septic abortion.

\section{Background}

Complications of abortion is the second highest cause of maternal death worldwide and may cause $13 \%$ of all pregnancy-related deaths $[1,2]$. Globally, 21 of 200 million annual pregnancies are terminated by unsafe abortion [1]. This figure has remained unchanged for the last decades [3]. The World Health Organization (WHO) defines unsafe abortion as 'a procedure for terminating an unintended pregnancy either by individuals without the necessary skills

\footnotetext{
* Correspondence: natjanorup@gmail.com

'Department of Obstetrics and Gynecology, Odense University Hospital, Odense, Denmark

Full list of author information is available at the end of the article
}

or in an environment that does not conform to minimum medical standards, or both' [4]. This definition may change according to a recent WHO bulletin as home administration of misoprostol is increasingly accessible as a safe abortion method [5].

Abortion rates are higher in countries with restrictive abortion laws [6, 7] and in Sub-Saharan Africa $97 \%$ of the abortions are estimated to be unsafe $[2,3]$. In South Africa the abortion law was liberalized in 1994, which was followed by a decrease in the incidence of abortion related infections by $52 \%$ and the mortality by over $90 \%$ [8]. In Uganda, as in the majority of SubSaharan African countries, induced abortion is illegal 
unless the pregnancy is a risk to the woman's life. Still, the most recent estimate indicates that 54 induced abortions per 1000 women of reproductive age were performed in 2003 , and $28 \%$ of these women were treated for complications [9]. Up to $50 \%$ of Ugandan women will hereby receive treatment for complications of an induced abortion during their life [9]. Septic abortion and haemorrhage are the most frequent life-threatening complications of unsafe abortion, and in 2008 it was estimated that $26 \%$ of maternal deaths in Uganda were accounted as abortion related complications [10].

In order to improve the circumstances of unsafe abortion, a 'post abortion care' (PAC) model has been developed and implemented in several countries with restrictive abortion laws, including Uganda [11]. Post abortion care focuses on better access to family planning methods and emergency care.

Manual vacuum aspiration (MVA) has been introduced in Uganda as a part of PAC. It has proved to be a safe method to evacuate first trimester abortions. When MVA is unavailable blunt curettage is recommended for first trimester abortions and always for second trimester abortions [12]. Sharp curettage (SC) is discouraged as it increases the risk of uterine perforations [12, 13]. Septic abortion is mainly caused by unsafe aseptic technique and retained intrauterine products. The infection can rapidly become life threatening and must be treated immediately at time of diagnosis by evacuation of the uterus [12]. MVA has improved access to emergency obstetric care as mid-level health providers can perform it safely even in peripheral health facilities [14].

A second method to improve access to PAC and the level of care is the use of the prostaglandin E1 analogue misoprostol for medical abortions [12, 15]. The method should be recommended for both first and second trimester abortions. Incomplete abortion and missed abortion with no signs of sepsis or severe haemorrhage can be managed safely with misoprostol and surgical procedures should be avoided [12]. The higher availability of misoprostol has also resulted in usage of the drug for illegal abortions $[2,5]$, though it is thought that this may decrease the frequency of complications [2].

Even though PAC has been introduced [11] and WHO regularly publishes guidelines for management of abortion complications in developing countries $[4,12,16]$ it is essential that the actual management performed is optimal and meets the recommendations [12, 17].

Criterion-based audit (CBA) has been used successfully in high-income countries to improve care in order to avoid complications during pregnancy, research suggests that the same applies in low- and middle-income countries $[18,19]$.

The objective of this study was by a retrospective partially completed criterion-based audit to evaluate the clinical assessment for life-threatening complications and the following management in women admitted with complications from abortion at a rural hospital in Uganda.

\section{Methods}

\section{Settings}

This study was carried out at a rural hospital in Southwestern Uganda. The hospital serves a population of 100,000 inhabitants providing 40,000 consultations annually. Clinical officers were responsible for the outpatient department where the women initially were assessed and management initiated. Two medical officers were in charge of the maternity ward, the adult ward, the HIV-department, the outpatient department and the surgical ward. Only medical officers performed the uterine evacuations. The maternity ward was further staffed with midwives, nurse-midwives and nurses. Nursing staff was present 24 hours a day and a medical officer was on call during night shifts. Induced abortion "on demand" was not performed at the hospital. Contraceptives were offered for free at family planning counselling before discharge.

\section{Population}

The sample size included all women admitted during a five-year retrospective period from January 2007 to April 2012. This period was chosen as the resources and opportunities to manage abortion complications at the hospital did not change during this period. Thus, uterine evacuation could not be performed prior to the inclusion period. Furthermore, the five-year period may eliminate selection bias such as seasonal variation in pregnancy incidence, opportunity to reach the hospital and variations in staff composition and experience.

\section{Inclusion and exclusion criteria}

Inclusion criteria were all women registered as admitted with incomplete, threatened, inevitable, missed and septic abortion. Cases were excluded if management only took place at the outpatient department, the women were referred during treatment or the abortion showed to be complete (Fig. 1). In these cases the results would be misleading since full management could not be assessed. Women with a gestational age above 28 weeks were excluded as deliveries from this point are considered a birth in Uganda. The diagnosis and gestational age was based on ultrasound in less than one third of the cases although not routinely used for threatened abortion. In cases where ultrasound was not applied the gestation age was established by last normal menstrual period or uterine size estimated by clinical or medical officers. 


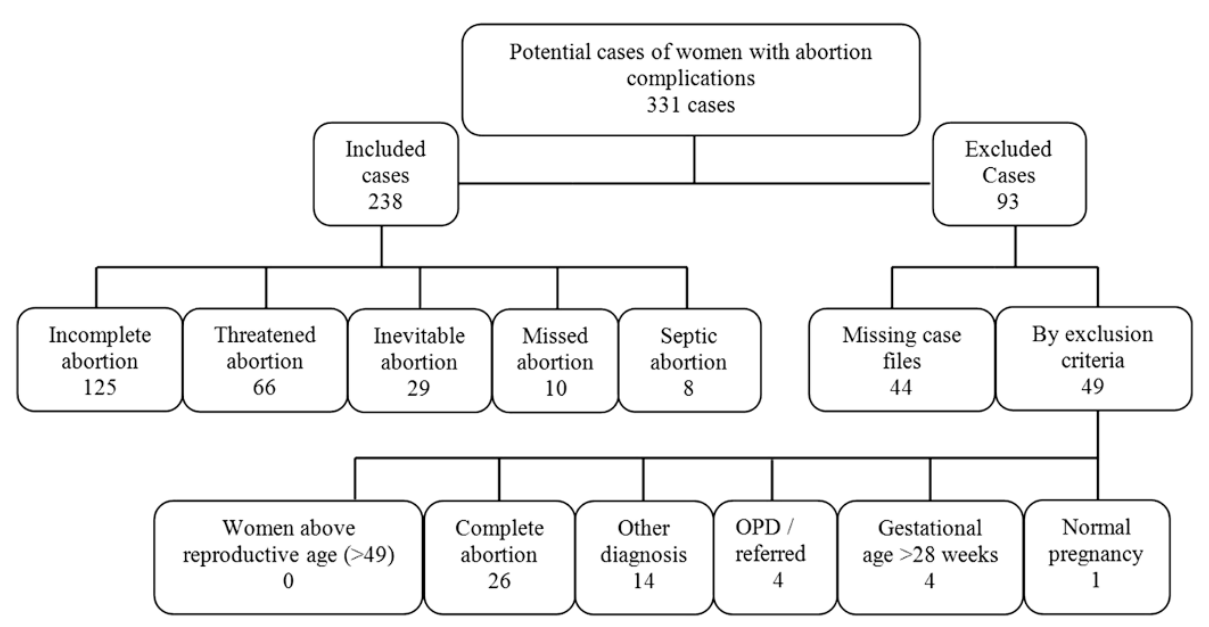

Fig. 1 Research material collected by inclusion of five abortion types and defined exclusion criteria. OPD: outpatient department

\section{Criterion-based audit cycle}

Steps one to three of the classic five-step CBA cycle were performed. These steps consist of establishment of criteria for good quality care, data collection and analysis of the findings. We could not complete the audit cycle by implementation of changes (step four) and re-evaluation (step five) because of time constraints. Preliminary results were instead presented to the staff and recommendations on how to improve practice in the future were discussed in plenary.

Step one - establishment of criteria for good quality care Step one was to establish realistic and relevant criteria for optimal assessment and management of abortion complications. The hospital's local standards for management turned out to be inaccurate, missing, incomplete and remarkably different from international standards (Table 1). Thus, manual vacuum aspiration was only part of the hospital's guideline regarding "unsafe abortion", and the guideline did not mention the importance of immediate evacuation at signs of sepsis or excessive bleeding, but only that it should be considered after stabilization of the patient with IV fluids and antibiotics. Furthermore, oxytocin and ergometrine should not be used for medical abortion and finally fluid resuscitation at a blood pressure $<100 \mathrm{mmHg}$ should be managed with two litres of fast running fluids.

Our criteria were selected based on acceptability, simplicity, feasibility and critical importance after reviewing international guidelines and national guidelines (Table 2) [12, 16, 17]. The national standards are published by the Ugandan Ministry of Health and based on WHO's guidelines [17]. The medical doctor in charge of the hospital ensured prior to the data collection that our audit criteria were realistic according to the local setting.

\section{Step two - data collection}

The data collection was performed from February to April 2012. Potential eligible cases were identified by provisional diagnosis from the maternity ward's admission-register, e.g. abortion, vaginal bleeding or abdominal pain. Based on the admission date from the register, we could identify the medical records anonymously from the archive and include or exclude due to the final diagnosis. To identify cases either not registered in the admission-books or registered differently in the admission book and the medical file all gynaecological case files in the archive were crosschecked. The contraceptive care registration system showed major differences compared to the maternity ward's register, and consequently we could not reliably identify the women's post-abortion contraceptive use. Accordingly, this resulted in the decision to exclude family planning as a part of the partially completed CBA. A standardized data collection form was pre-made and used to screen the medical records. In case a procedure was not documented, it was assessed as 'not performed'. The staff did not ask the women consistently whether they had had an illegal induction of the abortion, but when the women informed the staff it was documented in the medical file.

\section{Step three - analysis of the findings}

The third step was to compare the actual practice to the selected audit criteria. After the data collecting period the hospital received the data collection form and was 
Table 1 The hospital's guideline for management of abortion

\begin{tabular}{|c|c|}
\hline Initial assessment & Asses for shock and sepsis (fever, foul smelling discharge, hypotension, tachycardia). Give NS, at least 500 ml. \\
\hline \multirow{3}{*}{$\begin{array}{l}\text { Incomplete } \\
\text { abortion }\end{array}$} & $<16$ weeks and slight to moderate bleeding: use fingers or ring forceps to remove products protruding through the cervix. \\
\hline & $\begin{array}{l}<16 \text { weeks and bleeding is heavy: evacuation by SC. If evacuation is not immediately possible: } 0.2 \text { mg ergometrine IM or } 400 \\
\text { mcg misoprostol orally. }\end{array}$ \\
\hline & $\begin{array}{l}\text { >16 weeks: } 20 \text { IU oxytocin in } 1 \text { L IV NS until expulsion of POC.If necessary, give } 200 \text { mcg misoprostol vaginally every } 4 \text { hour until } \\
\text { expulsion, max } 800 \text { mcg. Evacuate any remaining POC }\end{array}$ \\
\hline $\begin{array}{l}\text { Threatened } \\
\text { abortion }\end{array}$ & Admit and treat with antibiotics. If abdominal pain, give analgesia. \\
\hline \multirow{2}{*}{$\begin{array}{l}\text { Inevitable } \\
\text { abortion }\end{array}$} & $<16$ weeks: give $10 \mathrm{IU}$ oxytocin and plan for evacuation ${ }^{\mathrm{a}}$. \\
\hline & >16 weeks, no active bleeding ${ }^{\mathrm{b}}$ : await spontaneously expulsion. Control pain. If necessary, infuse oxytocin 20 IU in 1 L IV NS. \\
\hline Unsafe abortion & $\begin{array}{l}\text { Assess for complications, injuries and sepsis. If blood pressure }>100 \mathrm{mmHg} \text { give } 500 \mathrm{ml} \mathrm{NS} \text {, if }<100 \mathrm{mmHg} 1 \mathrm{~L} \text {. Give antibiotics. } \\
\text { When stable, consider MVA. }\end{array}$ \\
\hline
\end{tabular}

A guideline for missed abortion did not exist

$I M$ intramuscular, $I U$ international units, $I V$ intravenous, $L$ litre, $m c g$ micrograms, $m g$ milligrams, $m /$ millilitres, $m m H g$ millimetres of mercury, $M V A$ manual vacuum aspiration, NS normal saline, POC products of conception, SC sharp curettage

${ }^{a}$ No recommendation for type of evacuation procedure

${ }^{\mathrm{b}}$ No recommendations for procedure for inevitable abortion above 16 weeks of gestational age and active bleeding

encouraged to continue the cycle by implementing the suggested changes and re-evaluate the management.

\section{Statistics}

Data were continuously entered into Microsoft Access. IBM SPSS 20.0 was used to calculate mean, median and standard deviation.

Table 2 Audit Criteria for acceptable management

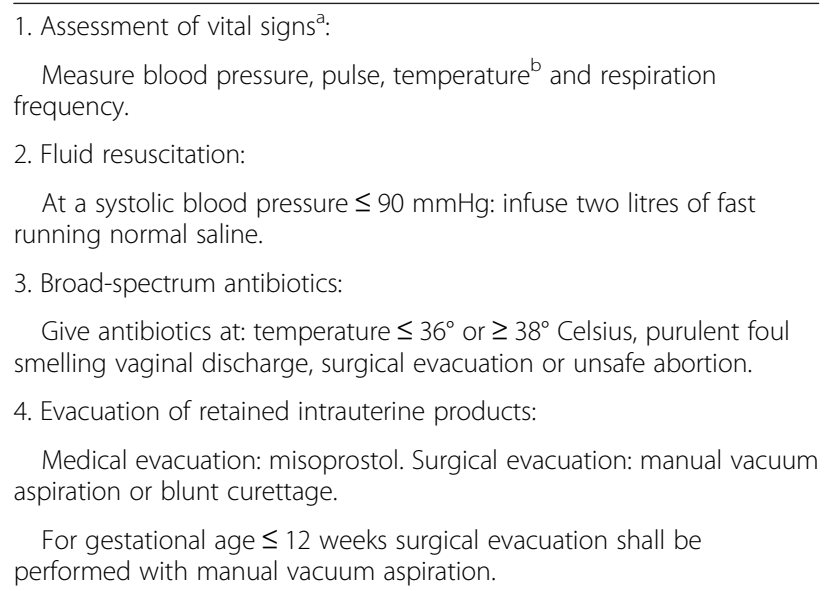

Give antibiotics at: temperature $\leq 36^{\circ}$ or $\geq 38^{\circ}$ Celsius, purulent foul smelling vaginal discharge, surgical evacuation or unsafe abortion.

4. Evacuation of retained intrauterine products:

Medical evacuation: misoprostol. Surgical evacuation: manual vacuum aspiration or blunt curettage.

For gestational age $\leq 12$ weeks surgical evacuation shall be performed with manual vacuum aspiration.

Expectant management is only recommended when the wellinformed patient wish to use this method and no additional complications are present.

5. Pain management:

Any expression of pain shall result in analgesics to the patient.

6. Waiting time for evacuation at sepsis or heavy bleeding:

Acute emergency evacuation of the uterus must be performed. This shall not be delayed by expectant antibiotic treatment but performed immediately.

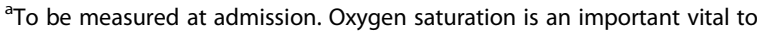
monitor, but the ward did not have the equipment to perform the measurement

${ }^{\mathrm{b}}$ Axil measurement, $0.5^{\circ}$ was therefore added to the raw data to compensate

\section{Ethics}

The hospital and its personnel have been kept anonymous. Ethical permission from the hospital to conduct the study was obtained prior to the study from the hospital' $\mathrm{s}$ authorities and made available for review by the Editor of this journal. The Danish National Committee on Biomedical Research Ethics in Denmark have assessed the project and found that no further ethical approvals for the analyses were necessary according to Danish law.

\section{Results}

We identified 331 potential cases. Of these, 238 met the inclusion criteria (Fig. 1). Registered abortion complications were distributed as follows; incomplete abortion $52.5 \%$, threatened abortion $27.7 \%$, inevitable abortion $12.2 \%$, missed abortion $4.2 \%$, and septic abortion $3.4 \%$.

Missing cases accounted for 44/331 (13.3 \%). Twentyone $(47.7 \%)$ of these had septic abortion as provisional diagnosis compared to $8(3.4 \%)$ in the included cases.

Population characteristics are presented in Table 3. More than one in five had previously had an abortion and $55.5 \%$ of the women were in second trimester mainly according to last menstrual period. Ultra-sound was used to determine gestational age in 70 women (29.4\%).

One case $(1 / 238)$ strictly fulfilled all the audit criteria (Table 4).

\section{Assessment of vital signs}

Temperature was recorded for $194(81.5 \%)$, blood pressure for 163 (68.8\%), pulse for 96 (40.3\%) and respiration frequency for eight $(3.4 \%)$ women. All four vital signs were measured in seven women $(2.9 \%)$ (Table 4$)$. 
Table 3 Population characteristics

\begin{tabular}{|c|c|}
\hline Women's characteristic & \\
\hline Age, mean $\pm S D$ & $26 \pm 6.9$ \\
\hline \multicolumn{2}{|l|}{ Marital status ${ }^{a}, \mathrm{n}(\%)$} \\
\hline Married & $140(59.3)$ \\
\hline Single & $2(0.8)$ \\
\hline nd & $94(39.8)$ \\
\hline \multicolumn{2}{|l|}{ Trimester $^{\mathrm{b}}, \mathrm{n}(\%)$} \\
\hline 1 & $70(33.2)$ \\
\hline 2 & $117(55.5)$ \\
\hline nd & $24(11.4)$ \\
\hline \multicolumn{2}{|l|}{ HIV infection, n (\%) } \\
\hline Yes & $7(3.0)$ \\
\hline No & $106(44.9)$ \\
\hline Deny test & $4(1.7)$ \\
\hline nd & $119(50.4)$ \\
\hline \multicolumn{2}{|l|}{ Previous abortion, n (\%) } \\
\hline Yes & $54(22.9)$ \\
\hline No & $78(33.1)$ \\
\hline nd & $104(44.1)$ \\
\hline Gravida $^{c}$, median \pm SD & $3 \pm 3$ \\
\hline Parity $^{c}$, median $\pm \mathrm{SD}$ & $1 \pm 3$ \\
\hline \multicolumn{2}{|l|}{ Gravida and (parity), $\mathrm{n}$} \\
\hline 0 & $0(57)$ \\
\hline 1 & $47(39)$ \\
\hline 2 & $42(22)$ \\
\hline 3 & $20(15)$ \\
\hline 4 & $19(10)$ \\
\hline $5+$ & $56(40)$ \\
\hline
\end{tabular}

nd not documented, SD standard deviation

${ }^{a}$ Two cases of incomplete abortion were readmissions due to insufficient prior management. The demographic data, except trimester, are only included for the first admission

${ }^{\mathrm{b}}$ Two cases admitted with inevitable and 25 threatened abortion are not included in 'trimester'; the pregnancy continued

${ }^{c}$ Not documented for all cases

\section{Fluid resuscitation}

A systolic blood pressure $\leq 90 \mathrm{mmHg}$ or less was recorded in 37 (15.5\%) women while intravenous fluid was not administered to $24(64.9 \%)$ of these. The criteria for fluid resuscitation were met by $35.1 \%$ (Table 4 ). Seven $(87.5 \%)$ of the eight diagnosed with sepsis did not receive intravenous fluids.

\section{Administration of broad-spectrum antibiotics}

Antibiotic treatment was indicated in 140 cases and received by 134 (95.7\%), while 92 out of 98 (93.9\%) without indication had prescribed antibiotics. In total $58.8 \%$ thereby met the criteria for antibiotics (Table 4).

\section{Evacuation of retained intra-uterine products}

Surgical evacuation was performed in 98 women. Fourteen $(14.3 \%)$ were evacuated by MVA, and of these five (35.7 \%) were in second trimester. Sixty-eight (69.4 \%) were evacuated by $\mathrm{SC}$, and of these 37 (54.4\%) were in second trimester. Three women (3.0\%) were evacuated by blunt curettage. The surgical evacuation method was not documented in 13 cases (13.3\%). Thirty (62.5\%) of the surgically evacuated second trimester abortions were above 15 week of gestation. Medical evacuation was used in 80 women and of these misoprostol was used in 41 cases $(51.3 \%)$. The remaining cases $(48.7 \%)$ received oxytocin, ergometrine or combinations of these with or without misoprostol. One septic abortion was tried evacuated by oxytocin. In total 36 cases $(23.5 \%)$ met the criteria for evacuation of retained intrauterine products (Table 4).

\section{Analgesia}

The criteria for pain management was met in 160 women (87\%) (Table 4).

\section{Timing for evacuation at sepsis or heavy bleeding}

Timing for evacuation at signs of sepsis or excessive bleeding could not be evaluated due to lack of documentation. Bleeding amount was poorly documented and time was only documented by date. Six women (75\%) with septic abortion had surgical evacuation of retained products. Two were evacuated during admission day, two were postponed one day, and two women were evacuated two days after their admission.

Ten women (4.2\%) had an unsafe abortion. One had consulted a private clinic, two had unknown herbal medicine installed in the birth canal, one had wild grass in the cervix, one had triggered the abortion with unknown medicine and one had received an unknown injection. No information was available regarding the method for the last four women. One woman had a traumatized cervix but denied to have induced the abortion. The case fatality rate was $2 / 238$ (0.84 \%). One woman died due to an unsafe septic abortion. In this case SC was postponed until two days after admission. Another woman died due to haemorrhage although she received fluid resuscitation and blood transfusions, but she had no evacuation of the retained products.

\section{Discussion}

This is to our knowledge the only partially completed CBA study evaluating the quality of clinical assessment for life-threatening complications and management of abortion related complications in a low-income country.

Our study identified suboptimal care in both the initial clinical assessment for life-threatening complications and 
Table 4 Assessment for life-threatening complications and management

\begin{tabular}{|c|c|c|c|c|c|c|c|c|c|c|c|c|}
\hline \multirow{3}{*}{$\begin{array}{l}\text { Fulfilment of the } \\
\text { criteria }\end{array}$} & \multicolumn{2}{|c|}{ Incomplete } & \multirow{2}{*}{\multicolumn{2}{|c|}{$\begin{array}{l}\text { Threatened } \\
n=66\end{array}$}} & \multirow{2}{*}{\multicolumn{2}{|c|}{$\frac{\text { Inevitable }}{n=29}$}} & \multirow{2}{*}{\multicolumn{2}{|c|}{$\frac{\text { Missed }}{n=10}$}} & \multirow{2}{*}{\multicolumn{2}{|c|}{$\frac{\text { Septic }}{n=8}$}} & \multirow{2}{*}{\multicolumn{2}{|c|}{$\frac{\text { Total }}{n=238}$}} \\
\hline & \multicolumn{2}{|c|}{$n=125$} & & & & & & & & & & \\
\hline & $\mathrm{n}$ & $\%$ & $\mathrm{n}$ & $\%$ & $n$ & $\%$ & $\mathrm{n}$ & $\%$ & $\bar{n}$ & $\%$ & $\mathrm{n}$ & $\%$ \\
\hline \multicolumn{13}{|l|}{ Vital signs } \\
\hline Yes & 4 & 3.2 & 2 & 3.0 & 1 & 3.4 & 0 & 0.0 & 0 & 0.0 & 7 & 2.9 \\
\hline No & 121 & 96.8 & 64 & 97.0 & 28 & 96.6 & 10 & 100.0 & 8 & 100.0 & 231 & 97.1 \\
\hline \multicolumn{13}{|l|}{ Fluid resuscitation } \\
\hline Yes & 11 & 47.8 & 0 & 0.0 & 1 & 25.0 & 0 & 0.0 & 1 & 50.0 & 13 & 35.1 \\
\hline No & 12 & 52.2 & 8 & 100.0 & 3 & 75.0 & 0 & 0.0 & 1 & 50.0 & 24 & 64.9 \\
\hline \multicolumn{13}{|l|}{ Antibiotics } \\
\hline Yes & 86 & 68.8 & 30 & 45.5 & 11 & 37.9 & 5 & 50.0 & 8 & 100.0 & 140 & 58.8 \\
\hline No & 39 & 31.2 & 36 & 54.5 & 18 & 62.1 & 5 & 50.0 & 0 & 0.0 & 98 & 41.2 \\
\hline \multicolumn{13}{|l|}{ Evacuation } \\
\hline Yes & 28 & 25.7 & 2 & 13.3 & 2 & 13.3 & 4 & 50.0 & 0 & 0.0 & 36 & 23.5 \\
\hline No & 81 & 74.3 & 13 & 86.7 & 13 & 86.7 & 4 & 50.0 & 6 & 100.0 & 117 & 76.5 \\
\hline \multicolumn{13}{|l|}{ Analgesia } \\
\hline Yes & 71 & 78.0 & 55 & 96.5 & 20 & 90.9 & 7 & 100.0 & 7 & 100.0 & 160 & 87. \\
\hline No & 20 & 22.0 & 2 & 3.5 & 2 & 9.1 & 0 & 0.0 & 0 & 0.0 & 24 & 13.0 \\
\hline \multicolumn{13}{|l|}{ All criteria } \\
\hline Yes & 1 & 0.8 & 0 & 0.0 & 0 & 0.0 & 0 & 0.0 & 0 & 0.0 & 1 & 0.4 \\
\hline No & 124 & 9.2 & 66 & 100.0 & 29 & 100.0 & 10 & 100.0 & 10 & 100.0 & 237 & 99.6 \\
\hline
\end{tabular}

the following management in all but one case, not only according to our criteria, but even the hospital's own guidelines were not followed. This lack of consensus may cause misdiagnosis and incorrect treatment based on the clinicians' preference. Life-threatening complications may be overlooked, as well as failure to perform fluid resuscitation and evacuation of the uterus at signs of shock and sepsis. These deficiencies are related to maternal death $[20,21]$. Furthermore, the method used in more than half of the evacuations are discouraged due to an increased risk of uterine perforation [12, 13].

Recently it was documented that women who died from abortion complications waited significantly longer for treatment than patients with eclampsia and postpartum haemorrhage [22]. Likewise, others have shown that the achieved awareness of this delay in treatment led to a major reduction in treatment delay as well increased willingness to improve practice [23]. These observations are in agreement with ours demonstrating that postponement of treatment may result in adverse outcome. Delayed management was observed in both cases of maternal death in our study and these may have been avoided if the midwives performed immediate MVA, which they can perform as safely as medical doctors [14]. Unfortunately, MVA was not available due to lack of sterilizing equipment, which is a well-known reason for substandard care $[13,21,24,25]$. However, the mortality rate we observed was comparable to other studies in similar settings [26, 27].

Furthermore, our results documented that the personnel were either unaware of guidelines or were not capable of following them. The results also documented an inadequate regular update of the local guidelines. Thus, a major informative work is necessary to improve knowledge and the use of guidelines, especially if this is a common problem in rural areas and it contributes to the maternal mortality from abortions.

The strength of the study is the systematic approach of the parts of CBA with criteria established beforehand minimizing the risk of bias from subjective assessment. A Cochrane review including 19 studies evaluating CBA in low-income countries reported improved obstetric management in 18 studies, though not in relation to post abortion care [28]. However, our study has some limitations. We did not complete the audit cycle and consequently the possible impact on improving care cannot be observed. Further, it relies fully on the written documentation available. The reliability of the documented data should be questioned, because what was actually done might not have been written down. Furthermore, our study could not systematically document if complications were due to unsafe abortions, as this was not systematically documented.

Thus, our observations represent only the audited hospital. It is impossible to say to what extent our 
observations are comparable to the management of abortion complications in developing countries in general. Completing the CBA and assessing several hospitals would have strengthened our results.

The hospital in our study used premade sheets at admittance where only temperature had to be documented and consequently, we observed this parameter to be the most frequently documented vital sign. Further, we observed a high proportion of missing cases and nearly half of them were recorded as septic abortion at admission. This observation questions a report from Pirkle et al. [29] who indicates that missing files were mostly random and was anticipated not to affect the results. This discrepancy from the study of Pirkle et al. [29] may be due to the poor documentation and consequently incorrect provisional diagnosis.

In two hospital-based studies from Tanzania $52 \%$ to $63 \%$, respectively of women with abortion complications admitted to have had an unsafe abortion, when interviewed with an empathetic approach [30,31]. This large number of women undergoing unsafe abortion contrasts our study. We observed few unsafe abortions and this can explain the surprisingly low number of septic abortions. One explanation might be the more widespread use of misoprostol, which has been described in several studies [2,5]. Although this may limit the number of unsafe abortions and consequently sepsis, it is impossible to assess whether an informal use of misoprostol exists in this geographic area. Thus this phenomenon needs to be explored more intensively. Another explanation to the low number of septic abortions could be the poor documentation and that some septic patients may have been overlooked due to missing recording of vital data.

It is interesting that more than half of the cases in our study were in second trimester whereas most spontaneous abortions takes place in the first trimester. It must be kept in mind however, that gestational age can be inaccurate when established by fundal height or last normal menstrual period as compared to ultra-sound as gold standard [32].

We suggest that future audits on complications of abortions include prospective data collection, timing of events and contraceptive counselling. There is an urgent need to upgrade the admittance sheet with fields for documentation of the necessary parameters to diagnose lifethreatening conditions. Subsequently, a clear flowchart for management should be developed to improve practice and consistency of treatment and finally a structured case file system may act to avoid the missing cases.

The staff's awareness of the actual substandard management [23] combined with delegating responsibilities to the personnel, e.g. the development of the flowchart and re-evaluation of the implemented changes, may increase the motivation to raise the standards for clinical practice.

Furthermore, we suggest that future audits complete the audit cycle in order to observe potential improvement in actual management and patient outcomes. Such a study needs to be locally anchored and the success will depend on the motivation of staff and time consumption [19]. In order to increase the success rate we suggest that an audit only includes a few central criteria like vital signs, fluid resuscitation at low blood pressure, emergency evacuation at signs of septic abortion or excessive bleeding and contraceptive counselling.

\section{Conclusion}

Our study revealed that guidelines were not followed resulting in suboptimal care. This was especially due to missing documentation of vital signs necessary to diagnose life-threatening complications, poor fluid resuscitation at signs of shock, and delayed evacuation of the uterus at septic abortion. In order to optimize suboptimal care we suggest that future audits are completed and carried out prospectively with local ownership. Improved motivation may be achieved by delegation of the responsibility locally thereby increasing the usefulness of the admittance sheet. Creation of a flowchart may increase implementation of any changes thereby ensuring better clinical practice.

\section{Abbreviations}

CBA: Criterion-based audit; MVA: Manual vacuum aspiration; SC: Sharp curettage; WHO: World Health Organization.

\section{Competing interests}

The authors declare that they have no competing interests.

\section{Authors' contributions}

The study originates from the Department of Obstetrics and Gynaecology, Odense University Hospital, Denmark, but the fieldwork and data collection was carried out at a rural hospital in Uganda. NM developed the study design, participated in the selection of audit criteria, performed the collecting of data, analysis and interpretation of data, drafted the article, and did final approval of the version to be published. BLS participated in development of study design by critically revising the audit criteria, repeated critical revision of analysis and interpretation, revised the article, and did final approval of the version to be published. GKK participated in development of study design by critically revising the audit criteria, repeated critical revision of analysis and interpretation, revised the article, and did final approval of the version to be published. MR participated in development of study design by critically revising the audit criteria, repeated critical revision of analysis and interpretation, revised the article, and did final approval of the version to be published.

\section{Acknowledgements}

Thank you to the hospital for giving us the opportunity to conduct the study, for their kindness, and for their comprehensive cooperation during the study.

\section{Author details}

${ }^{1}$ Department of Obstetrics and Gynecology, Odense University Hospital, Odense, Denmark. ${ }^{2}$ Centre for Innovative Medical Technology, University of Southern Denmark, Odense, Denmark. ${ }^{3}$ Department of Surgery, Makerere University college of Health sciences, Kampala, Uganda. 
Received: 27 November 2014 Accepted: 3 September 2015

Published online: 20 September 2015

\section{References}

1. World Health Organization. Unsafe abortion: global and regional estimates of the incidence of unsafe abortion and associated mortality in 2008. 6th ed. Geneva, Switzerland: WHO; 2011.

2. Guttmacher Institute, World Health Organization. Facts on Induced Abortion Worldwide. New York, USA and Geneva, Switzerland: Guttmacher Institute; 2012. p. 4

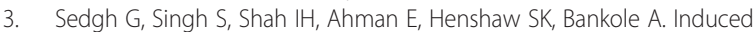
abortion: incidence and trends worldwide from 1995 to 2008. Lancet. 2012;379:625-32.

4. World Health Organization. The Prevention and Management of Unsafe Abortion. Geneva, Switzerland: WHO; 1993. p. 23.

5. Ganatra B, Tunçalp Ö, Johnston HB, Johnson Jr BR, Gülmezoglu AM, Temmerman M. From concept to measurement: operationalizing WHO's definition of unsafe abortion. Bull World Health Organ. 2014;92:155.

6. Berer M. National laws and unsafe abortion: the parameters of change. Reprod Health Matters. 2004;12(24 Suppl):1-8.

7. Rasch V. Unsafe abortion and postabortion care - an overview. Acta Obstet Gynecol Scand. 2011;90:692-700.

8. Jewkes $\mathrm{R}$, Rees $\mathrm{H}$, Dickson K, Brown $\mathrm{H}$, Levin J. The impact of age on the epidemiology of incomplete abortions in South Africa after legislative change. BJOG. 2005;112:355-9.

9. Singh S, Prada E, Mirembe F, Kiggundu C. The incidence of induced abortion in Uganda. Int Family Plan Perspect. 2005;31:183-91.

10. Guttmacher Institute, CEHURD (Center for Health, Human Rights and Development). Fact sheet: abortion in Uganda. Kampala, Uganda and New York, USA: Guttmacher Institute; 2013. p. 2

11. Curtis C. Meeting health care needs of women experiencing complications of miscarriage and unsafe abortion: USAID's postabortion care program. J midwifery Womens Health. 2007:52:368-75.

12. World Health Organization. Safe abortion: technical and policy guidance for health systems. 2nd ed. Geneva, Switzerland: WHO; 2012.

13. USAID, Rasch V, Huber D, E.O.Akande. Report of the postabortion care technical advisory panel. Washington, USA: USAID; 2007. p. 13.

14. Renner RM, Brahmi D, Kapp N. Who can provide effective and safe termination of pregnancy care? A systematic review. BJOG. 2013;120:23-31.

15. Misoprostol in Obstetrics and Gynaecology. http://www.misoprostol.org/wp-content/uploads/Misoprostol_DosageRecommendations-2012.pdf.

16. World Health Organization. Safe abortion: technical and policy guidance for health systems. Geneva, Switzerland: WHO; 2003.

17. Ministry of Health. Uganda Clinical Guidelines. National Guidelines on Management of Common Conditions. Kampala, Uganda: Ministry of Health; 2012. p. 368-71.

18. World Health Organization. Beyond the Numbers: Reviewing maternal deaths and complications to make pregnancy safer. Geneva, Switzerland: WHO; 2004.

19. Wagaarachchi PT, Graham WJ, Penney GC, McCaw-Binns A, Yeboah Antwi K, Hall MH. Holding up a mirror: changing obstetric practice through criterion-based clinical audit in developing countries. Int J Gynaecol Obstet. 2001;74:119-30.

20. Jacob ST, Banura P, Baeten JM, Moore CC, Meya D, Nakiyingi L, et al. The impact of early monitored management on survival in hospitalized adult Ugandan patients with severe sepsis: a prospective intervention study. Crit Care Med. 2012:40:2050-8.

21. Mbonye AK, Asimwe JB, Kabarangira J, Nanda G, Orinda V. Emergency obstetric care as the priority intervention to reduce maternal mortality in Uganda. Int J Gynaecol Obstet. 2007;96:220-5.

22. Mayi-Tsonga S, Oksana L, Ndombi I, Diallo T, de Sousa MH, Faundes A. Delay in the provision of adequate care to women who died from abortion-related complications in the principal maternity hospital of Gabon. Reprod Health Matters. 2009;17:65-70.

23. Mayi-Tsonga S, Assoumou P, Ole BS, Ntamack JB, Meye JF, Souza MH, et al. The contribution of research results to dramatic improvements in postabortion care: Centre Hospitalier de Libreville, Gabon. Reprod Health Matters. 2012;20:16-21.
24. Pearson L, Shoo R. Availability and use of emergency obstetric services: Kenya, Rwanda, Southern Sudan, and Uganda. Int J Gynaecol Obstet. 2005;88:208-15.

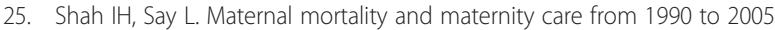
uneven but important gains. Reprod Health Matters. 2007;15:17-27.

26. Gebreselassie H, Fetters T, Singh S, Abdella A, Gebrehiwot Y, Tesfaye S, et al. Caring for women with abortion complications in Ethiopia: national estimates and future implications. Int Perspect Sex Reprod Health. 2010;36:6-15.

27. Gebreselassie H, Gallo MF, Monyo A, Johnson BR. The magnitude of abortion complications in Kenya. BJOG. 2005;112:1229-35.

28. Ivers N, Jamtvedt G, Flottorp S, Young JM, Odgaard-Jensen J, French SD, et al. Audit and feedback: effects on professional practice and healthcare outcomes. Cochrane Database Syst Rev. 2012;6:Article ID CD000259.

29. Pirkle CM, Dumont A, Traore M, Zunzunegui MV. Validity and reliability of criterion based clinical audit to assess obstetrical quality of care in West Africa. BMC Pregnancy Childbirth. 2012;12:118.

30. Rasch V, Kipingili R. Unsafe abortion in urban and rural Tanzania: method, provider and consequences. Trop Med Int Health. 2009;14:1128-33.

31. Rasch V, Massawe S, McHomvu Y, Mkamba M, Bergstrom S. A longitudinal study on different models of postabortion care in Tanzania. Acta Obstet Gynecol Scand. 2004:83:570-5.

32. Jehan I, Zaidi S, Rizvi S, Mobeen N, McClure EM, Munoz B, et al. Dating gestational age by last menstrual period, symphysis-fundal height, and ultrasound in urban Pakistan. Int J Gynaecol Obstet. 2010;110:231-4.

\section{Submit your next manuscript to BioMed Central and take full advantage of:}

- Convenient online submission

- Thorough peer review

- No space constraints or color figure charges

- Immediate publication on acceptance

- Inclusion in PubMed, CAS, Scopus and Google Scholar

- Research which is freely available for redistribution 